\title{
Anthroposophic Therapy for Migraine: A Two-Year Prospective Cohort Study in Routine Outpatient Settings
}

\author{
Harald J. Hamre*, ${ }^{*}$, Claudia M. Witt ${ }^{2}$, Gunver S. Kienle ${ }^{1}$, Anja Glockmann ${ }^{1}$, Renatus Ziegler ${ }^{3}$, \\ Andreas Rivoir ${ }^{4}$, Stefan N. Willich ${ }^{2}$ and Helmut Kiene ${ }^{1}$
}

${ }^{1}$ Institute for Applied Epistemology and Medical Methodology, Freiburg, Germany; ${ }^{2}$ Institute for Social Medicine, Epidemiology, and Health Economics, Charité University Medical Center, Berlin, Germany; ${ }^{3}$ Society for Cancer Research, Arlesheim, Switzerland; ${ }^{4}$ AnthroMed Öschelbronn, Center for Integrative Medicine, Niefern-Öschelbronn, Germany

Abstract: Background and Methods: Anthroposophic treatment for migraine is provided by physicians and includes special artistic and physical therapies and special medications. We conducted a prospective cohort study of 45 consecutive adult outpatients (89\% women) starting anthroposophic treatment for migraine under routine conditions. Main outcomes were Average Migraine Severity (physician and patient ratings 0-10, primary outcome), Symptom Score (patient rating, 010), and quality of life (SF-36); main follow-up time point was after six months.

Results: The anthroposophic treatment modalities used were medications (67\% of patients), eurythmy therapy (38\%), art therapy $(18 \%)$, and rhythmical massage therapy $(13 \%)$. Median therapy duration was 105 days. In months $0-6$, conventional prophylactic antimigraine medications were used by $14 \%(\mathrm{n}=5 / 36)$ of evaluable patients.

From baseline to six-month follow-up, physician-rated Average Migraine Severity improved by 3.14 points (95\% confidence interval 2.40-3.87, p<0.001); patient-rated Average Migraine Severity improved by 2.82 points (2.05-3.64, $\mathrm{p}<0.001$ ); and Symptom Score improved by 2.32 points $(1.68-2.95, \mathrm{p}<0.001)$. In addition, three SF-36 scales (Social Functioning, Bodily Pain, Vitality), the SF-36 Physical Component summary measure, and the SF-36 Health Change item improved significantly. All improvements were maintained at last follow-up after 24 months. Patients not using conventional prophylactic antimigraine medications had improvements similar to the whole cohort.

Conclusions: Patients with migraine under anthroposophic treatment had long-term improvement of symptoms and quality of life. Although the pre-post design of the present study does not allow for conclusions about comparative effectiveness, study findings suggest that anthroposophic therapies may be useful in the long-term care of patients with migraine.

Keywords: Anthroposophy, combined modality therapy, drug therapy, eurythmy therapy, migraine, prospective studies.

\section{INTRODUCTION}

Migraine affects $14 \%$ of adults in Europe every year [1] and is associated with substantial disability, reduced quality of life, reduced work capacity, psychiatric and somatic comorbidity, and increased healthcare use [2-4]. The World Health Organization has ranked severe migraine attacks among the most disabling medical conditions, along with psychosis, dementia, and quadriplegia [5]. Up to threefourths of patients with acute migraine attacks do not become pain free from 5-HT1 agonists ("triptanes") [6, 7] and half of patients will not respond to prophylactic medications [6]. Many migraine patients use complementary therapies [810], sometimes provided by their physicians.

Anthroposophic medicine (AM) is a physician-provided complementary therapy system founded by Rudolf Steiner and Ita Wegman in the 1920s [11]. AM extends the conception of human physiology beyond cellular and molecular mechanisms to holistic interactions of over-riding functional

*Address correspondence to this author at the Institute for Applied Epistemology and Medical Methodology, Zechenweg 6, D-79111 Freiburg, Germany; Tel: +49 761 1560307; Fax: +49 761 1560306;

E-mail: harald.hamre@ifaemm.de systems (downward causality [12]). In particular, a complex equilibrium exists between two polar systems: the 'nervesense system' (low metabolic rate, mediator of consciousness) and the 'metabolic system' of the abdominal organs (high metabolic rate, minimal consciousness). This equilibrium can be distorted in human disease. In migraine, a predominance of the metabolic system (with symptoms such as nausea, vomiting, diarrhea, abdominal cramps) leads to disturbances in the nerve-sense system (e. g. headache, sensory hypersensitivity, visual disturbances) [13-15]. This imbalance is sought to be regulated by special AM therapies (eurythmy movement exercises, art therapy, rhythmical massage therapy) [16] and special AM medications [14, 15, 17, 18].

Eurythmy therapy is an artistic exercise therapy involving cognitive, emotional and volitional elements. In eurythmy therapy sessions the patients exercise specific movements with the hands, the feet or the whole body. Eurythmy movements are related to the sounds of vowels and consonants, to music intervals or to soul gestures, e. g. sympathy-antipathy. Between therapy sessions the patients exercise eurythmy movements daily. In AM art therapy the patients engage in painting, drawing, clay modelling, music or speech exercises. Rhythmical massage therapy was devel- 
oped from Swedish massage; special techniques include lifting movements, rhythmically undulating gliding movements, and complex movement patterns like lemniscates [19].

AM medications are prepared from plants, minerals, animals and from chemically defined substances and can be prepared in concentrated or potentised form. Potentization implies a successive dilution, each dilution step involving a rhythmic succussion (repeated shaking of liquids) or trituration (grinding of solids into lactose monohydrate). For example, a D6 potency (also called 6X) has been potentized in a 1:10 dilution six times, resulting in a $1: 10^{-6}$ dilution [20]. Since potencies beyond D23 do not contain any molecules of the original substance, effects cannot readily be explained by molecular mechanisms. However, a systematic review of invitro studies found biological effects of potencies $\geq$ D23 in nearly three-fourths of the studies and in more than twothirds of the studies with highest quality [21]. All AM medications are manufactured according to Good Manufacturing Practice and national drug regulations; quality standards of raw materials and manufacturing methods are described in the Anthroposophic Pharmaceutical Codex [20]. The available evidence suggests that AM medications and therapies are generally well tolerated with infrequent adverse reactions of mostly mild to moderate severity $[19,22]$.

AM therapy is practised by physicians (counselling, AM medication) and non-medical therapists (eurythmy, art, rhythmical massage) in 67 countries worldwide [23]. AM therapy providers are certified following structured training programs according to international, standardized curricula. Therapy guidelines exist for AM medical therapy [24], eurythmy therapy [25], and AM art therapy [26]. AM is practised in general practice and in specialist fields, including neurology, and is also integrated into intensive care and emergency medicine provided in hospitals, including university teaching hospitals [19]. For patients with migraine, the physician will choose among the available AM therapy modalities in order to tailor the treatment to individual needs of the patient. AM treatments can be administered alone or combined with conventional antimigraine medications [14].

Several studies have evaluated acute or prophylactic therapy for migraine with Ferrum-Quartz [19], a mixture of ferrous sulphate, honey and quartz, available as $150 \mathrm{mg}$ capsules and $10 \mathrm{mg}$ tablets ('Kephalodoron' or 'Biodoron' tablets) [20]. Here we present a pre-planned subgroup analysis of migraine patients from a study of a broader range of AM therapy options (eurythmy therapy, art therapy, rhythmical massage therapy, medications) [27].

For complementary therapy systems in widespread use, regardless of whether evidence from randomized trials exists, it has been argued that the conventional drug research strategy - starting with studies of biological mechanisms and moving through Phase I, II and III clinical trials - is not optimal [28]. Another, more appropriate strategy has been proposed, moving from descriptive studies ('Phase 1') towards comparative studies of the whole system and its parts, and ending with studies of biological mechanisms ('Phase 5') [28]. In the context of this reversed strategy, the present analysis addressed topics in the Phases 1-2 (therapy paradigms, therapy use, clinical outcomes, perceived benefit, safety).

\section{MATERIALS AND METHODOLOGY}

\section{Study Design and Objective}

This is a prospective two-year cohort study in a realworld medical setting. The study was initiated by the health insurance company Innungskrankenkasse Hamburg as part of a research project on the effectiveness, costs, and safety of AM therapies in outpatients with chronic disease (Anthroposophic Medicine Outcomes Study, AMOS) [27, 29, 30]. The present pre-planned analysis concerned the subgroup of adult patients with migraine. Since this was the first prospective study of comprehensive AM treatment for this indication, the primary objective was to describe AM therapy for migraine (characteristics of AM therapy users, spectrum of AM therapy modalities used, extent of combination with conventional anti-migraine therapy) as well as clinical outcomes after AM treatment under routine conditions. Further research questions addressed the use of health services, adverse reactions, and therapy satisfaction.

\section{Setting, Participants, and Therapy}

All physicians certified by the Physicians' Association for Anthroposophical Medicine in Germany and working in an office-based practice or outpatient clinic were invited to participate in the AMOS study. Certification as an AM physician required a completed medical degree and a three-year structured postgraduate training. The participating physicians recruited consecutive patients starting AM therapy under routine clinical conditions. Patients enrolled from 1 January 1999 to 31 December 2005 were included in the analysis if they fulfilled the eligibility criteria. Inclusion criteria were:

1. Age 17-75 years.

2. A diagnosis of migraine according to the criteria of the International Headache Society [31], assessed by the Kieler Kopfschmerzfragebogen, a standardized headache questionnaire in the German language [32;33], documented by the patients (for patients enrolled before April 2001: physician's diagnosis, assisted by a brief written clinical description). In accordance with the clinical practice guidelines of the Drug Commission of the German Medical Association [34], neuroimaging was not required for routine diagnostics of all patients.

3. Starting AM therapy for migraine:

- AM-related consultation of at least 30 minutes followed by new prescription of AM medication,

- or new referral to AM therapy (art, eurythmy or rhythmical massage).

Patients were excluded if they had previously received the AM therapy in question (see inclusion criteria 3) for migraine. Patients were treated according to the physician's discretion. AM therapy was evaluated as a whole system [35]. Additional costs for AM treatments were 0.1-5.2 Euro per daily dose of an AM medication (51 different price groups, median 0.2 Euro, mean 0.8 Euro); 20-32 Euro per AM therapy session; and 46 Euro and 92 Euro for AM consultations with physicians of $30 \mathrm{~min}$ and $60 \mathrm{~min}$ duration, respectively. These costs were reimbursed by some but not all German health insurance companies. 


\section{Clinical Outcomes}

Primary outcomes were physician- and patient-rated Average Migraine Severity, documented on numerical rating scales [36] from 0 ("not present") to 10 ("worst possible"), at six-month follow-up.

Secondary clinical outcomes were Symptom Score and quality of life. Symptom Score, the severity of one to six most relevant symptoms present at baseline, was assessed by patients on numerical rating scales from 0 ("not present") to 10 ("worst possible"). Quality of life was assessed with the SF-36 Health Survey [37] (Physical and Mental Component summary measures, eight scales, Health Change item).

Physician-rated Average Migraine Severity was documented after 0 and 6 months, while all other clinical outcomes were documented after $0,3,6,12,18$, and 24 months.

\section{Other Outcomes}

Therapy outcome rating (0-10), satisfaction with therapy $(0-10)$ and therapy effectiveness rating ("very effective, "effective", "less effective", "ineffective" or "not evaluable") were documented by the patients after 6 and 12 months.

Adverse reactions to medications or therapies were documented by the patients after $6,12,18$ and 24 months and by the physicians after 6 months. The documentation included cause, intensity (mild / moderate $/$ severe $=$ no / some / complete impairment of normal daily activities), and therapy withdrawal due to adverse reactions. Serious adverse events were documented by the physicians throughout the study.

\section{Data Collection}

All data were documented with questionnaires returned in sealed envelopes to the study office. The physicians documented eligibility criteria; the therapists documented AM therapy administration; all other items were documented by the patients, unless otherwise stated. The patient responses were not made available to the physicians. The physicians were compensated 40 Euro (after March 2001: 60 Euro) per included and fully documented patient, while the patients received no compensation.

The data were entered twice by two different persons into Microsoft ${ }^{\circledR}$ Access 97 (Microsoft Corp., Redmond, WA, USA). The two datasets were compared and discrepancies resolved by checking with the original data. Non-AM medications were coded according to the Anatomical Therapeutic Chemical Classification Index.

\section{Quality Assurance, Adherence to Regulations}

The study was approved by the Ethics Committee of the Faculty of Medicine Charité, Humboldt University, Berlin, Germany, and was conducted according to the Declaration of Helsinki and largely following the ICH Guideline for Good Clinical Practice E6. Written informed consent was obtained from all patients before enrolment.

\section{Data Analysis}

The data analysis was performed for all patients fulfilling the eligibility criteria, using SPSS ${ }^{\circledR}$ 14.0.1 (SPSS Inc., Chicago, Ill, USA) and StatXact ${ }^{\circledR}$ 5.0.3 (Cytel Software Corporation, Cambridge, MA, USA). T-test was used for continu- ous data with normal distribution; Wilcoxon Signed-Rank test was used for paired continuous data with non-normal distribution; McNemar test and Fisher's exact test were used for dichotomous data. All tests were two-tailed. Significance criterion was $p<0.05$. Since this was a descriptive study, no adjustment for multiple comparisons was performed [38]. Pre-post effect sizes were calculated as Standardized Response Mean $(=$ mean change score divided by the standard deviation of the change score) and classified as minimal (< $0.20)$, small (0.20-0.49), medium (0.50-0.79), and large $(\geq$ $0.80)[39,40]$. Clinical outcomes were analyzed with replacement of missing values by the last value carried forward.

Two pre-planned sensitivity analyses (SA1-SA2) were performed to assess the influence of natural recovery and adjunctive therapy on the 0-6-month outcome of physicianand patient-rated Average Migraine Severity. SA1 concerned natural recovery, which was assumed to be unlikely in patients with disease duration of at least one year [41]. The sample was therefore restricted to patients with disease duration of at least 12 months prior to study enrolment. SA2 concerned the effects of prophylactic antimigraine medications: The sample was restricted to patients not using prophylactic antimigraine medications during the first six study months.

\section{RESULTS}

\section{Participating Physicians and Therapists}

The patients were enrolled by 30 physicians with four different qualifications (27 general practitioners, one neurologist, one internist, and one gynaecologist). Comparing these physicians to AM-certified physicians in Germany with the same four qualifications but without study patients $(\mathrm{n}=225)$, no significant differences were found regarding gender (60.0\% vs. $58.5 \%$ males), number of years in practice $(16.1 \pm 6.9$ vs. $19.3 \pm 8.9)$, and the proportion of physicians working in primary care $(90.0 \%$ vs. $92.0 \%)$. Mean age was $44.9 \pm 5.9$ and $48.3 \pm 8.0$ years in physicians with and without study patients, respectively (mean difference 3.4 years, $95 \%$ confidence interval 0.4-6.3 years, $\mathrm{p}=0.027$ ).

The patients were treated by 31 different AM therapists (art, eurythmy, rhythmical massage). Comparing these therapists to certified therapists without study patients $(\mathrm{n}=$ 1137), no significant differences were found regarding gender ( $87.1 \%$ vs. $80.7 \%$ women), age (mean $48.2 \pm 9.3$ vs. 50.3 \pm 9.4 years) or the number of years since therapist qualification (10.5 \pm 6.9 vs. $13.2 \pm 8.7$ years $)$.

\section{Patient Recruitment and Follow-Up}

A total of 79 patients starting AM therapies for headache were screened for inclusion. Of these patients, 45 fulfilled all eligibility criteria and were included in the analysis. 34 patients were not included; in 27 of these patients the eligibility criteria were not fulfilled (the indication for AM therapy was not migraine but another headache disorder). The remaining seven patients were potentially eligible but not included for the following reasons: patients' baseline questionnaire missing $(\mathrm{n}=3)$, physician's baseline documentation missing $(\mathrm{n}=$ 3 ), patients' and physicians' baseline questionnaire dated > 30 days apart $(\mathrm{n}=1)$.

A total of $89 \%$ (40/45) of patients were enrolled by general practitioners, while $11 \%$ were enrolled by specialists. 
The physicians' settings were primary care practices (89\% of evaluable patients, $n=39 / 44)$, referral practice $(7 \%, n=3)$, and outpatient clinics $(5 \%, \mathrm{n}=2)$.

The last patient follow-up ensued on 9 May 2007. A total of $96 \%(n=43 / 45)$ of patients returned at least one followup questionnaire. The patients were administered a total of 225 follow-up questionnaires, out of which 157 (70\%) were returned. Follow-up rates were $89 \%(\mathrm{n}=40 / 45), 76 \%, 69 \%$, $60 \%$, and $56 \%$ after $3,6,12,18$, and 24 months, respectively. Respondents $(n=34)$ and non-respondents $(n=11)$ of the six-month follow-up questionnaire did not differ significantly regarding age, gender, disease duration or baseline parameters (physician- and patient-rated Average Migraine Severity, Symptom Score). Corresponding dropout analysis for the 24-month follow-up also showed no significant differences between respondents $(n=25)$ and non-respondents $(\mathrm{n}=20)$. The physician six-month follow-up documentation was available for $82 \%(n=37 / 45)$ of patients.

\section{Baseline Characteristics}

The patients were recruited from 12 of 16 German federal states. Mean age was $39.5 \pm 11.1$ years (range 17-61 years, Table 1). A total of $89 \%(n=40 / 45)$ of the patients were women. Median duration of the migraine disorder was
12.0 years (interquartile range $[\mathrm{IQR}]$ 2.5-20.0, range 4 months to 40 years, mean $13.6 \pm 10.1$ years). The number of days with headache in the past month was documented in patients enrolled after March $2001(\mathrm{n}=23)$ and was 1 day in $4 \%(\mathrm{n}=1 / 23), 2-6$ days in $61 \%(\mathrm{n}=14), 7-10$ days in $26 \%$ $(\mathrm{n}=6), 11-15$ days in $0 \%(\mathrm{n}=0)$, and $>15$ days in $9 \%(\mathrm{n}=$ 2), with a median number of 5.0 days (mean $6.8 \pm 6.3$ days).

A current comorbid disease was present in $78 \%(35 / 45)$ of patients. Most common comorbid diseases, classified by the International Statistical Classification of Diseases and Related Health Problems, 10th Revision, were F00-F99 Mental and Behavioural Disorders $(24 \%, \mathrm{n}=17$ of 70 diagnoses), N00-N99 Diseases of the Genito-urinary System (17\%), L00-L99 Diseases of the Skin and Subcutaneous Tissue (13\%), and M00-M99 Musculoskeletal Diseases (9\%). Further baseline data are presented in Table $\mathbf{1}$.

\section{Therapy}

\section{AM Therapies}

At study enrolment, the duration of the consultation with the AM physician was $<30 \mathrm{~min}$ in $40 \%(\mathrm{n}=18 / 45)$ of patients, 30-44 min in $40 \%, 45-59$ min in $9 \%$, and $\geq 60 \mathrm{~min}$ in $11 \%$. At enrolment $22 \%(n=10 / 45)$ of patients fulfilled In-

Table 1. Baseline Data of Study Population

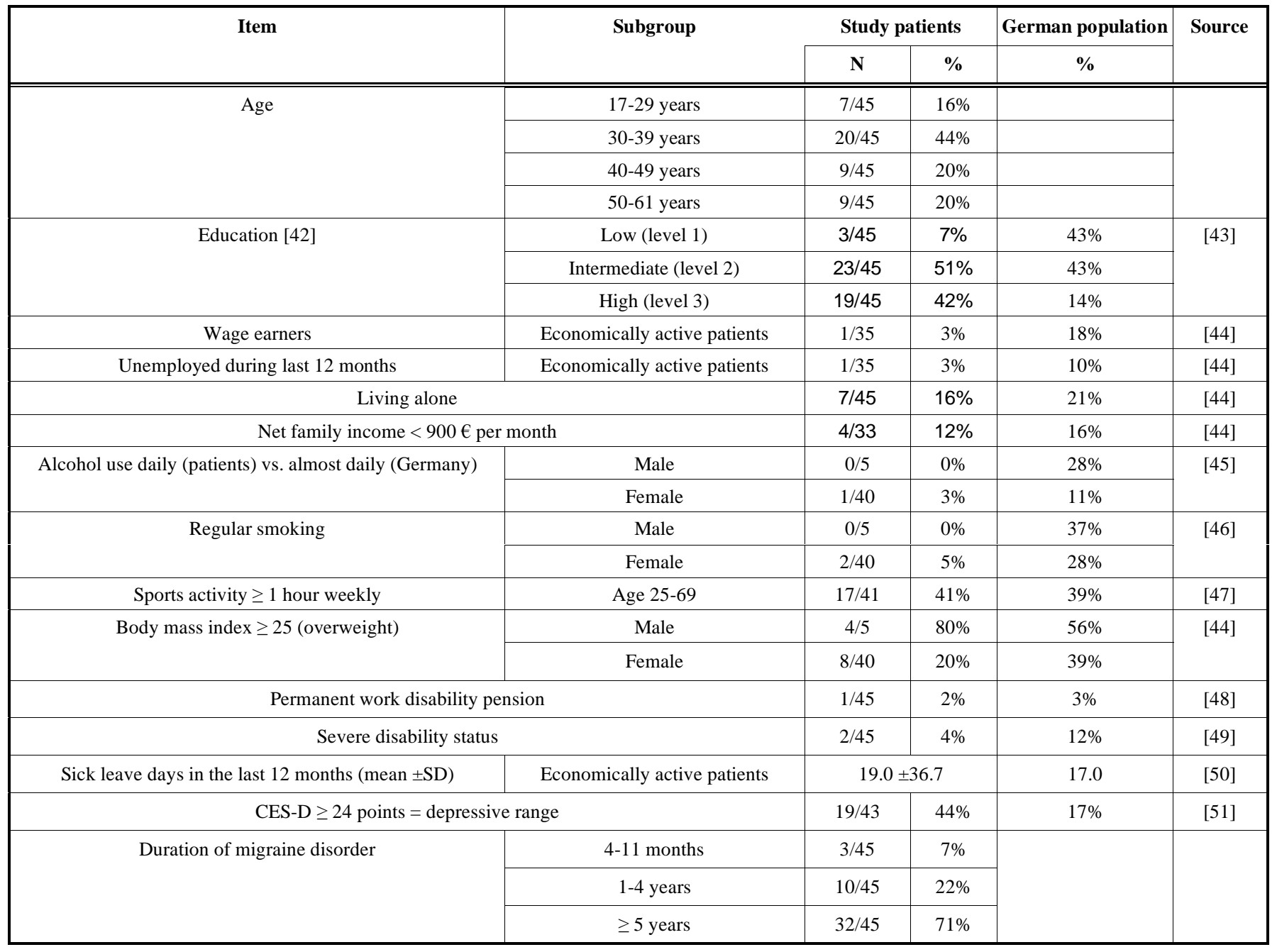

CES-D: Center for Epidemiological Studies Depression Scale, German version. 
clusion Criterion 3a (AM-related consultation of $\geq 30 \mathrm{~min}$ utes followed by new prescription of AM medication), $38 \%$ $(\mathrm{n}=17$ ) fulfilled Inclusion Criterion $3 \mathrm{~b}$ (referral to AM art, eurythmy or rhythmical massage therapy), and $40 \%(n=18)$ fulfilled Inclusion Criteria $3 \mathrm{a}$ and $3 \mathrm{~b}$. Of the 35 patients referred to AM art/eurythmy/massage therapy, $89 \%(\mathrm{n}=31)$ had the planned AM therapy, 3\% $(\mathrm{n}=1)$ did not have AM therapy, and for $9 \%(n=3)$ the AM therapy documentation is incomplete. AM therapies used were eurythmy therapy (n $=17$ patients $)$, rhythmical massage therapy $(n=6)$, and art therapy $(\mathrm{n}=8)$. The AM eurythmy/art/massage therapy started median 9 (IQR 0-35) days after enrolment. Median therapy duration was 105 days (IQR 77-246 days), median number of therapy sessions was 12 (IQR 10-20). AM medications were used by $67 \%(\mathrm{n}=30 / 45)$ of patients. The most frequently used AM medications in months 0-6 were Ferrum-Quartz ( $\mathrm{n}=14$ patients, thereof $\mathrm{n}=7$ using $150 \mathrm{mg}$ capsules and $\mathrm{n}=7$ using $10 \mathrm{mg}$ tablets), and Phosphorous dilution ( $\mathrm{n}=3$ patients - contains potentised yellow phosphorus; used by the three patients in a D5, D6, and D20 potency, respectively).

\section{Use of Conventional Antimigraine Medications in Months 0-6}

Medications to treat acute migraine attacks were used by $53 \%(\mathrm{n}=19 / 36)$ of evaluable patients; medication groups used were non-opioid analgesics (44\%), non-steroid antiinflammatory agents (6\%), and 5-HT1 agonists (14\%). The total number of days with use of medication to treat acute migraine attacks in months 0-6 was $1-9$ days $(\mathrm{n}=9$ patients), 10-19 days $(\mathrm{n}=3)$, and 20-90 days $(\mathrm{n}=19)$. Prophylactic antimigraine medications were used by $14 \%(\mathrm{n}=5 / 36)$; medications used were antidepressants (8\%), cyclandelate $(3 \%)$, and flunarazine $(3 \%)$. The total number of days of use of prophylactic medications was 5 days $(\mathrm{n}=1), 60-180$ days $(\mathrm{n}=3)$, and unknown $(\mathrm{n}=1)$.

\section{Clinical Outcomes}

All clinical outcomes were improved from baseline at all subsequent follow-ups (exception: the SF-36 scale Role Emotional in months 0-6) (Table 2, Figs. 1-3). For seven of the 14 outcomes (physician- and patient-rated Average Migraine Severity, Symptom Score, the SF-36 scales Social Functioning, Bodily Pain, and Vitality and the SF-36 Health Change item) all improvements from baseline were significant at all follow-ups. Three further outcomes (SF-36 Physical and Mental Component summary measures, SF-36 scale Mental Health) were significantly improved at three or four out of five follow-ups.

At six-month follow-up, an improvement of $\geq 50 \%$ of baseline Average Migraine Severity was observed in 52\% (n $=23 / 44$ ) of evaluable patients for physician rating and $45 \%$ $(n=20 / 44)$ for patient rating. Effect sizes for the 0-6-month comparison were large for three outcomes (physician- and patient-rated Average Migraine Severity, Symptom Score), medium for three outcomes (SF-36 Social Function, Bodily Pain, Health Change), small for six outcomes, and minimal for two outcomes (Table 2).

We performed two sensitivity analyses of the 0-6-month outcome of physician- and patient-rated Average Migraine Severity (Table 3: SA1-SA2; see Methods for further description). For physician rating, the individual analyses resulted in a reduction of the average 0-6 month improvement

\section{Table 2. Clinical Outcomes 0-6 Months}

\begin{tabular}{|c|c|c|c|c|c|c|}
\hline Outcome (range) & $\mathbf{N}$ & $\begin{array}{c}0 \text { months } \\
\text { Mean (SD) }\end{array}$ & $\begin{array}{c}6 \text { months } \\
\text { Mean (SD) }\end{array}$ & \multicolumn{2}{|c|}{ 0-6 month difference* } & SRM \\
\hline $\begin{array}{l}\text { Average Migraine Severity, Physician } \\
\qquad(0-10)\end{array}$ & 44 & $7.20(1.37)$ & $4.07(2.48)$ & $3.14(2.40-3.87)$ & $<0.001$ & 1.30 \\
\hline $\begin{array}{l}\text { Average Migraine Severity, Patient ( } 0 \text { - } \\
10)\end{array}$ & 44 & $6.77(1.79)$ & $3.93(2.44)$ & $2.84(2.05-3.64)$ & $<0.001$ & 1.09 \\
\hline SF-36 Mental Component & 44 & $39.51(12.55)$ & $41.55(11.76)$ & $2.03(-1.07$ to 514$)$ & 0.194 & 0.20 \\
\hline \multicolumn{7}{|l|}{ SF-36 Scales (0-100) } \\
\hline Physical Function & 45 & $82.89(21.91)$ & $84.28(20.29)$ & $1.39(-3,25$ to 6.02$)$ & 0.549 & 0.09 \\
\hline Role Physical & 45 & $45.56(39.27)$ & $56.11(38.86)$ & $10.56(-0.94$ to 22.05$)$ & 0.071 & 0.28 \\
\hline Mental Health & 45 & $55.69(20.00)$ & $59.47(18.28)$ & $3.78(-0.80$ to 8.35$)$ & 0.103 & 0.25 \\
\hline Bodily Pain & 45 & $41.07(19.45)$ & $55.89(24.13)$ & $14.82(8.12$ to 21.53$)$ & $<0.001$ & 0.66 \\
\hline Vitality & 45 & $40.44(18.27)$ & $47.44(18.51)$ & $7.00(2.08$ to 11.92 & 0.006 & 0.43 \\
\hline General Health & 44 & $54.95(20.14)$ & $59.09(18.17)$ & $4.14(-0.70$ to 8.98$)$ & 0.092 & 0.26 \\
\hline SF-36 Health Change** & 45 & $3.16(1.02)$ & $2.40(1.18)$ & $0.76(0.31$ to 1.21$)$ & 0.001 & 0.51 \\
\hline
\end{tabular}

*Positive differences indicate improvement. **SF-36 Health Change: range from 1 ("much better now than one year ago") to 5 ("much worse now than one year ago"). SRM: Standardized Response Mean effect size (minimal: <0.20, small: 0.20-0.49, medium: 0.50-0.79, large: $\geq 0.80$ ). 


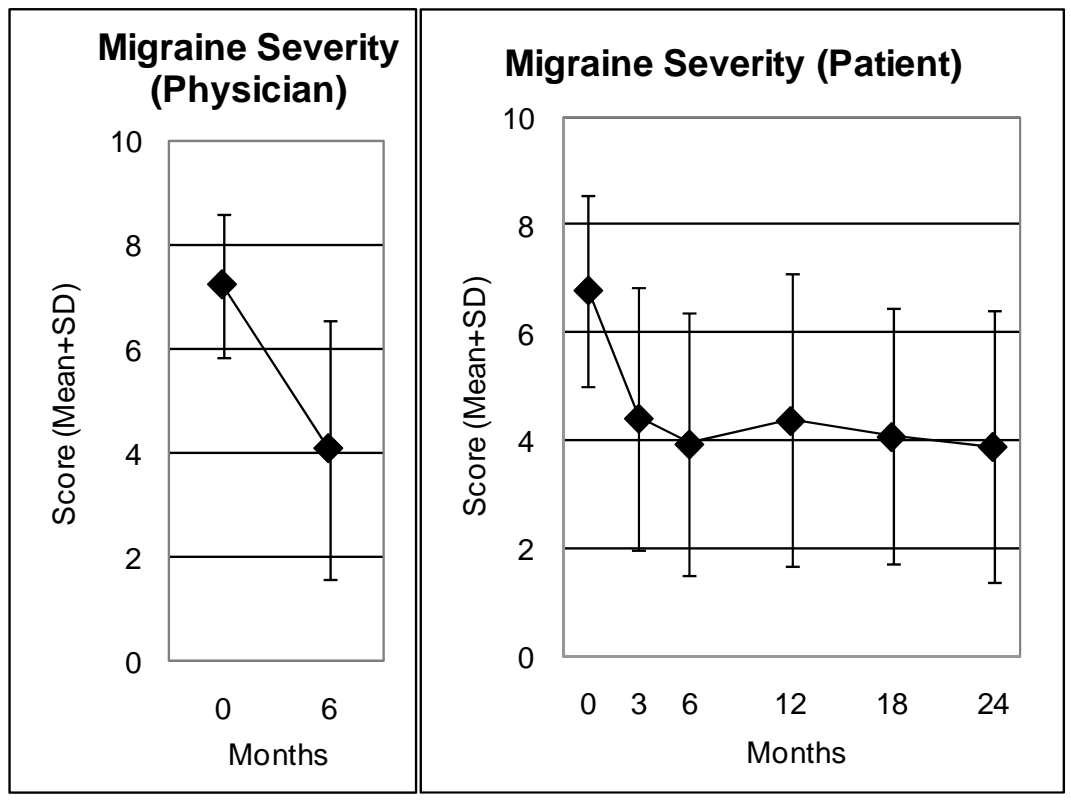

Fig. (1). Average Migraine Severity.

Range: 0 "not present", 10 "worst possible". Physician and patient ratings.

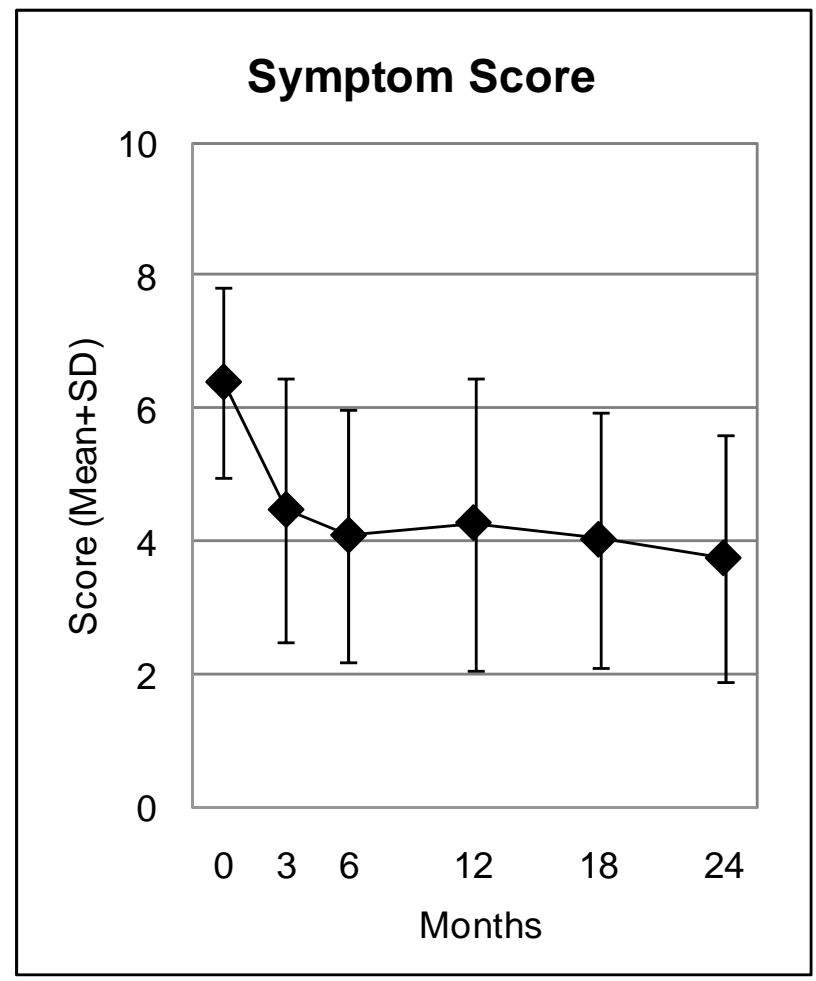

Fig. (2). Symptom Score.

Range: 0 "not present", 10 "worst possible".

of maximum $6 \%(3.14 \rightarrow 2.95$ points $)$. Combining both analyses, the improvement was reduced by $10 \%(3.14 \rightarrow 2.82$ points). For patient rating, the individual analyses resulted in a reduction of the improvement of maximum $8 \%$ $(2.94 \rightarrow 2.61$ points $)$. Combining both analyses, the improvement was reduced by $2 \%(2.84 \rightarrow 2.78$ points $)$.

\section{Other Outcomes}

At six-month follow-up, the patients' average therapy outcome rating (numeric scale from 0 "no help at all" to 10 "helped very well") was $7.33 \pm 2.42$ and patient satisfaction with therapy (from 0 "very dissatisfied" to 10 "very satisfied") was $7.72 \pm 2.05$. The patients' effectiveness rating of eurythmy, art or rhythmical massage therapy was positive ("very effective" or "effective") in $76 \%(n=19 / 25)$ of evaluable patients who had started therapy, and negative ("less effective", "ineffective" or "not evaluable") in $24 \%$. The ratings of therapy outcome, satisfaction and effectiveness did not change significantly between 6- and 12-month follow-up. 


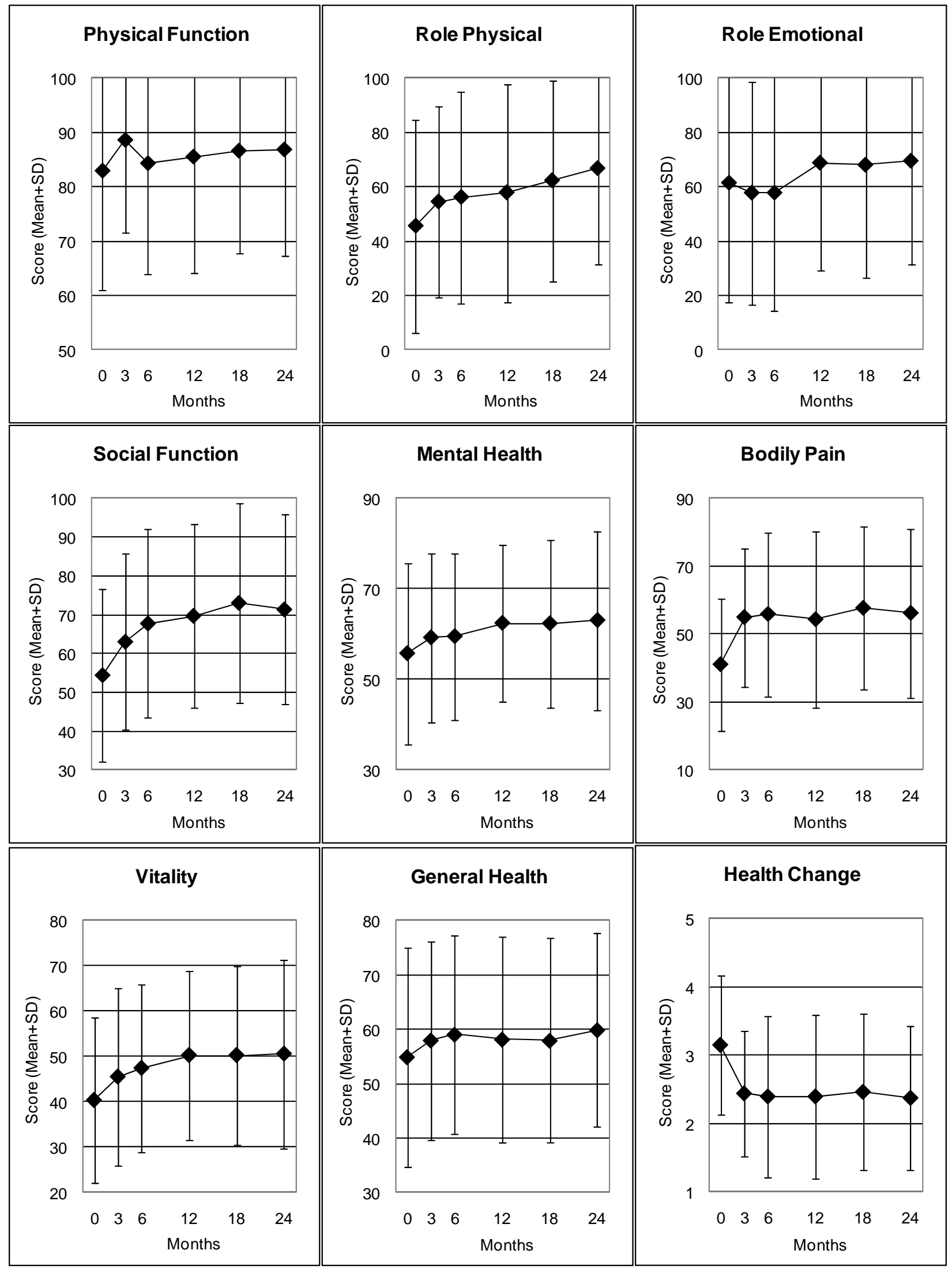

Fig. (3). SF-36 Scales, SF-36 Health Change Item.

SF-36 scales: Range 0-100, higher scores indicate better health. SF-36 Health Change: Range from 1 ("much better now than one year ago") to 5 ("much worse now than one year ago"). 
Table 3. Average Migraine Severity 0-6 Months: Sensitivity Analyses (SA)

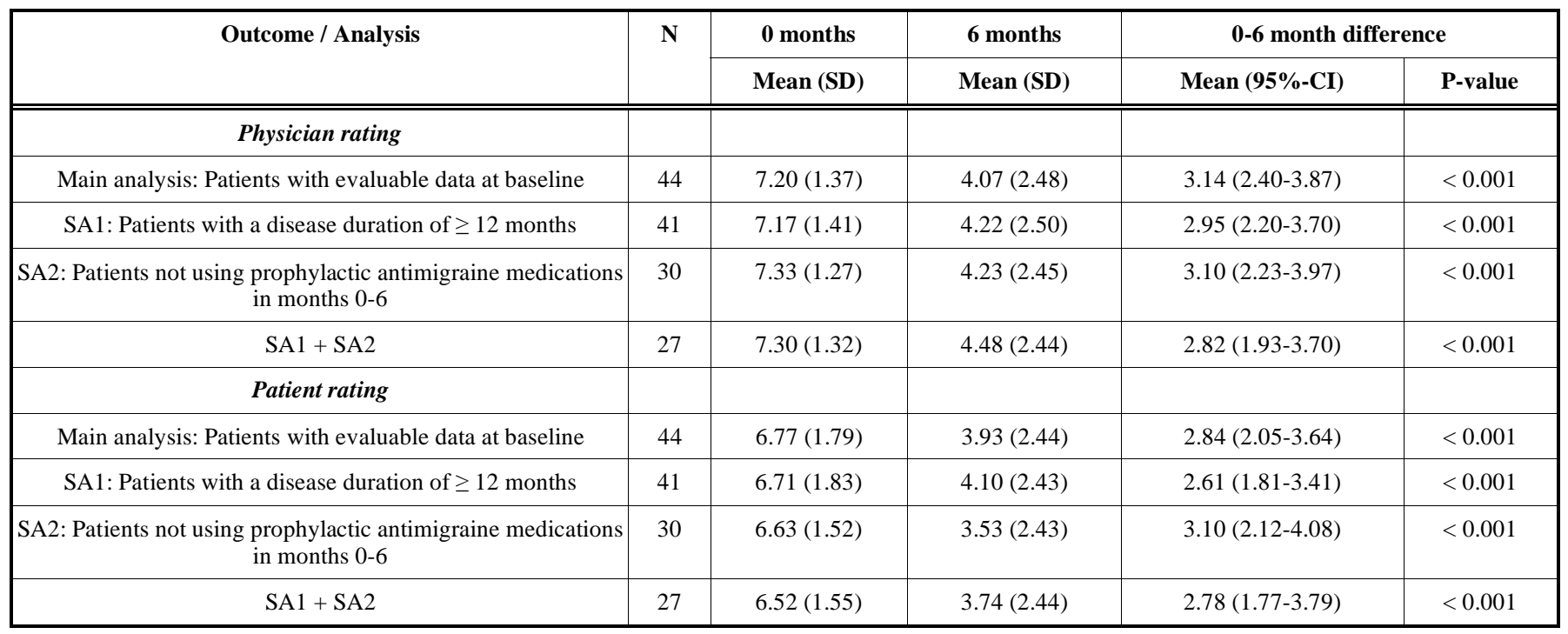

The frequency of reported adverse drug reactions was $3 \%$ ( $n=1$ of 30 users) for AM medications and $9 \%(n=3$ of 34 users) for non-AM medications $(p=0.616)$. Adverse drug reactions of severe intensity were reported in three patients using non-AM medications (unspecified psychic symptoms from homoeopathic arsenicum album; nightmares from amitriptyline; skin blisters from estradiol/norethisterone tablets), while medication was stopped due to reported adverse reactions in one patient using AM medication (skin blisters from rosemary ointment). No adverse reactions from nonmedication therapies occurred. No serious adverse events occurred.

\section{DISCUSSION}

This is the first prospective evaluation of comprehensive AM treatment for migraine. We aimed to obtain information on AM therapy for this indication under routine outpatient conditions in Germany and studied adults starting AM therapy for migraine. Two-thirds of patients used nonmedication AM therapies; two-thirds used AM medications; one in seven patients also used conventional prophylactic medications. Under AM treatment, significant and sustained improvements of migraine severity and quality of life were observed.

Strengths of this study include a detailed assessment of the therapy setting and therapy-related factors, a long followup period, and high representativeness: $11 \%$ of all AMcertified physicians seeing migraine patients in Germany participated; the participating AM physicians and therapists resembled all eligible physicians and therapists with respect to socio-demographic characteristics; and $87 \%$ of screened and eligible patients were enrolled. These features suggest that the study mirrors contemporary AM practice to a high degree.

To assess the routine clinical practice, where the selection of AM therapy options will vary according to individual needs, we analyzed AM as a whole system [35]. The sample size of AM therapy modality subgroups (eurythmy, art, rhythmical massage, medical) did not allow for subgroup analysis. The influence of the AM therapy modality and other therapy variables (e. g. duration of the consultation with the physician at study enrolment, number of AM therapy sessions) on clinical outcomes has been assessed in a multivariate analysis of adult AMOS patients with migraine and other chronic indications [52].

Another limitation in regard to sample size applies to the number of days with headache. This outcome, widely used in migraine studies, was only documented in a subset of patients, the documentation did not distinguish between migraine and interval headaches, and the number of patients with evaluable data at six-month follow-up $(n=13)$ did not allow for outcome analysis.

Since the study had a long recruitment period, the study physicians were not able to participate throughout the period and to screen and enrol all eligible patients (criteria: see Methods section). For a different subset of patients from the AMOS project (patients referred to AM therapies for any chronic indication and enrolled before 1 April 2001), it was estimated that physicians enrolled every fourth eligible patient [53]. This selection could bias results if physicians were able to predict therapy response and if they preferentially screened and enrolled such patients for whom they expected a particularly favorable outcome. In this case one would expect the degree of selection (= the proportion of eligible vs. enrolled patients) to correlate positively with clinical outcomes. That was not the case, the correlation was almost zero (Spearman-Rho -0.04, $\mathrm{p}=0.496, \mathrm{n}=364$ [53]). Likewise, another analysis of 500 adult patients enrolled into AMOS in the period 1999-2005 showed no correlation between the degree of selection and the 0-6 month difference of Symptom Score [52]. These analyses do not suggest that the participating physicians' expectations of future therapy response led to any selection bias affecting clinical outcomes.

A limitation of the study is the absence of a comparison group receiving conventional treatment or no therapy. Accordingly, one must consider several other causes for the observed improvements apart from the AM treatment. We therefore conducted a sensitivity analysis of physician- and 
patient-rated Average Migraine Severity, estimating the influence of natural recovery and adjunctive treatment with prophylactic antimigraine medications. These two factors together explained up to $10 \%$ of the 0-6 month improvement. Dropout rates increased from $11 \%$ after three months to $44 \%$ after 24 months. Dropouts and respondents had comparable baseline data, and in a telephone survey of non-respondents from a different subset of the AMOS sample, the proportion of patients with clinical deterioration at 24-month follow-up was comparable in dropouts and respondents [54]. In the outcome analyses, attrition bias was minimised by replacing missing values of clinical outcomes by the last value carried forward. Non-medication therapies such as acupuncture [55] or biofeedback [56] were not documented in the study and could therefore not be evaluated. According to a previous analysis from this research program [41], regression to the mean due to symptom fluctuation with preferential selfselection to therapy and study inclusion at symptom peaks explained up to 0.43 points $(11 \%)$ of the improvement of an outcome corresponding to physician-rated Average Migraine Severity in this analysis. Other possible confounders are psychological factors and non-specific effects. However, since AM therapy was evaluated as a whole system [35], the question of specific therapy effects vs. non-specific effects (placebo effects, context effects, physician-patient interactions, patient expectations etc.) was not an issue of the present analysis.

Because 14 clinical outcomes were analysed (Table 2), the issue of multiple hypothesis testing arises [38]. However, eight of the 14 comparisons at six-month follow-up showed significant improvements and six comparisons had p-values $\leq 0.001-$ a constellation that would not be expected to occur by chance. (E. g. a Bonferroni adjustment for 14 tests would have indicated $\mathrm{p}<0.004$ as significance level).

Since AM treatment was to be evaluated under routine conditions, therapy was administered at the discretion of the physicians and therapists and not according to standardized protocols. This raises the question of whether study interventions would be replicable in future studies. However, AM therapy providers worldwide are trained according to highly standardized curricula, specifying e. g. individual eurythmy movements for specific diseases, constitution types, and movement patterns. Therefore, relevant therapy differences across settings would not be expected. Moreover, in this study, any local therapy differences would probably be offset by the large number of participating AM physicians and therapists.

The present analysis was restricted to clinical outcomes and did not assess costs. In an analysis of 487 adult patients from the AMOS study with migraine and other chronic indications, costs of AM medications and therapies in the first study year amounted to $12 \%$ of all costs of healthcare and productivity loss [57]. These extra costs of the new AM treatment in AMOS were offset by a reduction of inpatient hospital costs [29, 57]. Other, comparative evaluations indicate similar or lower costs in AM therapy settings, compared to conventional settings $[19,58]$.

This study provides the first data on comprehensive AM treatment for migraine in AM settings. The female/male ratio in this predominantly primary care sample (8.0/1.0) was higher than among migraineurs in the population (3.0/1.0)
[59] and also higher than in primary care studies of AM medications for migraine (1.6-3.1/1.0) [60,61]. The higher proportion of women in this sample might possibly reflect that women are more likely than men to engage in creative therapies such as AM art and eurythmy therapy. The use of non-opioid analgesics (44\% of patients), 5-HT1 agonists $(14 \%)$, and prophylactic antimigraine agents (14\%) was similar to the use among migraineurs in Germany $[62,63]$ or France [64] during the study.

Baseline migraine disability, assessed by the number of days with headache in the past month (median 5.0 days), was higher than in the German population with migraine (median 2.2 days) [65], but the proportion of patients with $>10$ days with headache was similar (9\% vs. 12\%) [63]. Quality of life at baseline, assessed with the SF-36 Health Survey, was worse than in other migraine studies (median difference for all SF-36 scores in all evaluable studies: 0.42 standard deviations) [66]. The proportion of responders at six-month follow-up (patients with 50\% improvement of Average Migraine Severity from baseline: $45-52 \%$ ) was of the same order of magnitude as in trials of prophylactic antimigraine medications [6]. Notably, in prophylactic trials a response was defined as $50 \%$ reduction in number of migraine attacks, which was not documented in the present study; therefore this comparison is necessarily approximate. A systematic comparison of identical quality of life outcomes (SF-36) in migraine cohorts receiving other therapies showed improvements of largely of the same order of magnitude as in this study [66].

Previous studies have found beneficial effects of single AM medications on migraine [19]. In accordance with these findings, we found improvement of migraine symptoms and quality of life under comprehensive AM treatment. A notable finding was that three-fourths of study patients did not use anti-migraine medications in the first six months after enrolment, apart from non-opioid analgesics. Some migraine patients will not profit from medication; other patients stop taking medications due to adverse reactions or reject them, e. g. because they are passive. Even non-medication therapies for migraine are not suitable for all patients: some therapies are also passive (e. g. acupuncture or chiropractics) and others may be perceived as monotonous (e. g. biofeedback). In this context, the AM approach, with recourse to artistic exercise therapies as well as medication and rhythmical massage therapy, may be a welcome therapy option for some migraineurs.

\section{CONCLUSIONS}

In this study, adult migraine patients under AM treatment had long-term reduction of symptoms and improvement of quality of life. Improvements were similar in patients not using antimigraine prophylactic medications. Although the pre-post design of the present study does not allow for conclusions about comparative effectiveness, study findings suggest that AM therapies may be useful in the long-term care of patients with migraine.

\section{TRIAL REGISTRATION}

Not applicable (this is not a clinical trial). 


\section{ABBREVIATIONS}

$\begin{array}{ll} \pm & =\text { Standard deviation } \\ \text { AM } & =\text { Anthroposophic Medicine } \\ \text { AMOS } & \text { Anthroposophic Medicine Outcomes Study } \\ \text { IQR } & =\text { interquartile range } \\ \text { SA } & =\text { Sensitivity analysis }\end{array}$

\section{CONFLICT OF INTERESTS}

Within the last five years $\mathrm{HJH}$ and GSK have received restricted research grants from Wala-Heilmittel $\mathrm{GmbH}$ and Weleda AG, manufacturers of AM medications, otherwise all authors declare that they have no potential conflict of interests.

\section{ACKNOWLEDGEMENTS}

This study was funded by the Software-AG Stiftung and the Innungskrankenkasse Hamburg, with supplementary grants from the Christophorus-Stiftungsfonds in der GLS Treuhand e.V., the Mahle Stiftung, Wala Heilmittel GmbH and Weleda AG. The sponsors had no influence on design and conduct of the study; collection, management, analysis or interpretation of the data; or preparation, review or approval of the manuscript. We thank Wilfried Tröger for helpful discussions. Our special thanks go to the study physicians, therapists, and patients for participating.

\section{AUTHORS' CONTRIBUTIONS}

HJH, CMW, GSK, SNW, and HK contributed to study design. HJH, AG, AR, and HK contributed to data collection. HJH, RZ, and HK wrote the analysis plan, $\mathrm{HJH}$ and $\mathrm{AG}$ analyzed data. $\mathrm{HJH}$ was principal author of the paper, had full access to all data, and is a guarantor. All authors contributed to manuscript drafting and revision and approved the final manuscript.

\section{REFERENCES}

[1] Stovner LJ, Zwart JA, Hagen K, Terwindt GM, Pascual J. Epidemiology of headache in Europe. Eur J Neurol 2006; 13(4): 333-45.

[2] Lipton RB, Bigal ME. Ten lessons on the epidemiology of migraine. Headache 2007; 47(Suppl 1): S2-S9.

[3] Brandes JL. The migraine cycle: patient burden of migraine during and between migraine attacks. Headache 2008; 48(3): 430-41.

[4] Stovner LJ, Andree C. Impact of headache in Europe: a review for the Eurolight project. J Headache Pain 2008; 9(3): 139-46.

[5] Murray CJ, Lopez AD. Regional patterns of disability-free life expectancy and disability-adjusted life expectancy: Global Burden of Disease Study. Lancet 1997; 349(9062): 1347-52.

[6] Cady R, Dodick DW. Diagnosis and treatment of migraine. Mayo Clin Proc 2002; 77(3): 255-61.

[7] Silberstein SD. Migraine. Lancet 2004; 363(9406): 381-91.

[8] von Peter S, Ting W, Scrivani S, et al. Survey on the use of complementary and alternative medicine among patients with headache syndromes. Cephalalgia 2002; 22(5): 395-400.

[9] Rossi P, Di LG, Malpezzi MG, et al. Prevalence, pattern and predictors of use of complementary and alternative medicine (CAM) in migraine patients attending a headache clinic in Italy. Cephalalgia $2005 ; 25(7)$ : 493-506.

[10] Upchurch DM, Chyu L, Greendale GA, et al. Complementary and alternative medicine use among American women: findings from The National Health Interview Survey, 2002. J Womens Health (Larchmt ) 2007; 16(1): 102-13.

[11] Steiner R, Wegman I. Extending practical medicine. Fundamental principles based on the science of the spirit. [GA 27] [First published 1925]. Bristol: Rudolf Steiner Press; 2000.
[12] Campbell DT. Downward causation in hierarchically organized biological systems. In: Ayala FJ, Dobzhansky T, Eds. Studies in the philosophy of biology. London, Macmillan 1974; pp. 179-86.

[13] Schirmer F. Migräne aus schulmedizinischer und anthroposophischer Sicht. [Migraine from the point of view of conventional and anthroposophic medicine]. Der Merkurstab 1998; 51(6): 348-55.

[14] Rivoir A. Migräne. [Migraine]. Stuttgart: Verlag Freies Geistesleben \& Urachhaus; 2002.

[15] Sommer M. Stoffwechsel und Migräne. [Metabilism and migraine]. In: Medizinisches Seminar Bad Boll, editor. Anthroposophische Medizin in der Praxis, Band 2 [Anthroposophic medicine in clinical practice, Bad Boll, Natur Mensch Medizin Verlags GmbH 2002; vol. 2: pp. 229-46.

[16] Ritchie J, Wilkinson J, Gantley M, Feder G, Carter Y, Formby J. A model of integrated primary care: anthroposophic medicine. London: Department of General Practice and Primary Care, St Bartholomew's and the Royal London School of Medicine, Queen Mary, University of London; 2001.

[17] Wilde K, Leonhardt W. Vademecumskizze zum Thema Migräne und Kopfschmerzen [Therapy manual for migraine and headaches]. Beiträge zu einer Erweiterung der Heilkunst 1982; 35(3): 126-30.

[18] Fintelmann V. Intuitive Medizin. Einführung in eine anthroposophisch ergänzte Medizin [Intuitive medicine. Introduction to anthroposophic medicine]. $3^{\text {rd }}$ ed. Stuttgart: Hippokrates Verlag 1995.

[19] Kienle GS, Kiene H, Albonico HU. Anthroposophic medicine: effectiveness, utility, costs, safety. Stuttgart, New York: Schattauer Verlag 2006.

[20] Anthroposophic Pharmaceutical Codex APC, Second Edition. Dornach: The International Association of Anthroposophic Pharmacists IAAP 2007.

[21] Witt CM, Bluth M, Albrecht H, Weisshuhn TE, Baumgartner S, Willich SN. The in vitro evidence for an effect of high homeopathic potencies - a systematic review of the literature. Complement Ther Med 2007; 15(2): 128-38.

[22] Hamre HJ, Kiene H, Kienle GS. Clinical research in anthroposophic medicine. Altern Ther Health Med 2009; 15(6): 52-5.

[23] Annual Report 2005. Dornach: International Coordination Anthroposophic Medicine / IKAM. Medical Section at the Goetheanum; 2005.

[24] Guidelines for Good Professional Practice in Anthroposophic Medicine. International Federation of Anthroposophic Medical Associations. Last update: 2010. Accessibility verified: 11-12-2009. http://www.ivaa.info/?p=81

[25] Eurythmy Therapy Guideline. Filderstadt: Berufsverband Heileurythmie e.V. (Eurythmy Therapy Association); 2004.

[26] Pütz H. Leitlinie zur Behandlung mit Anthroposophischer Kunsttherapie (BVAKT) ${ }^{\circledR}$ für die Fachbereiche Malerei, Musik, Plastik, Sprachgestaltung [Guideline for treatment with Anthroposophic Art Therapy with the therapy modalities painting, music, clay, speech]. Filderstadt: Berufsverband für Anthroposophische Kunsttherapie e. V. [Association for Anthroposophic Art Therapy in Germany] 2008.

[27] Hamre HJ, Becker-Witt C, Glockmann A, Ziegler R, Willich SN, Kiene H. Anthroposophic therapies in chronic disease: The Anthroposophic Medicine Outcomes Study (AMOS). Eur J Med Res 2004; 9(7): 351-60.

[28] Fønnebø V, Grimsgaard S, Walach H, et al. Researching complementary and alternative treatments - the gatekeepers are not at home. BMC Med Res Methodol 2007; 7: 7.

[29] Hamre HJ, Witt CM, Glockmann A, Ziegler R, Willich SN, Kiene H. Health costs in anthroposophic therapy users: a two-year prospective cohort study. BMC Health Serv Res 2006; 6: 65.

[30] Hamre HJ, Witt CM, Glockmann A, Tröger W, Willich SN, Kiene H. Use and safety of anthroposophic medications in chronic disease: a 2-year prospective analysis. Drug Saf 2006; 29(12): 117389.

[31] Headache Classification Commitee of the International Headache Society. Classification and diagnostic criteria for headache disorders, neuralgias, and facial pain. Cephalalgia 1988; 8(Suppl 7): 196.

[32] Göbel H. Die Klassifikation von Kopfschmerzen: Kriterien und praktische Durchführung. [Classification of headache: criteria and practical implementation]. Z aerztl Fortb Qual sich 1993; 87(6): 451-8.

[33] Göbel H. Die Kopfschmerzen: Ursachen, Mechanismen, Diagnostik und Therapie in der Praxis. [Headaches: Causes, mechanisms, 
diagnostic and therapy in clinical practice]. Berlin, Heidelberg, New York: Springer-Verlag 1997.

[34] Empfehlungen zur Therapie von chronischen Kopf- und Gesichtsschmerzen. Inhaltlich abgestimmt mit der Deutschen Gesellschaft zum Studium des Schmerzes (DGSS) und der Deutschen Migräneund Kopfschmerzgesellschaft (DMKG) [Guidelines for treatment if chronic headache and facial pain. Consensus with the German Society for the Study of Pain and the German Migraine and Headache Society]. Cologne: Drug Commission of the German Medical Association 2001

[35] Boon H, MacPherson H, Fleishman S, et al. Evaluating complex healthcare systems: A critique of four approaches. Evid Based Complement Alternat Med 2007; 4(3): 279-85.

[36] Westhoff G. VAS Visuelle Analog-Skalen; auch VAPS Visual Analogue Pain Scales, NRS Numerische Rating-Skalen; Mod. Kategorialskalen [VAS Visual Analogue Scales; also VAPS Visual Analogue Pain Scales, NRS Numerical Rating Scales; Mod. Categorical Scales; Mod.]. Handbuch psychosozialer Messinstrumente. Göttingen, Hogrefe 1993; pp. 881-5.

[37] Bullinger M, Kirchberger I. SF-36 Fragebogen zum Gesundheitszustand. Handanweisung. [SF-36 Health Survey, German Version: Handbook]. Göttingen: Hogrefe-Verlag 1998.

[38] Feise RJ. Do multiple outcome measures require p-value adjustment? BMC Med Res Methodol 2002; 2: 8 .

[39] Cohen J. Statistical power analysis for the behavioral sciences. 2. ed. Hillsdale, NJ: Lawrence Erlbaum 1988.

[40] McDowell I. Measuring health. A guide to rating scales and questionnaires. $3^{\text {rd }}$ ed. Oxford: Oxford University Press 2006.

[41] Hamre HJ, Glockmann A, Kienle GS, Kiene H. Combined bias suppression in single-arm therapy studies. J Eval Clin Pract 2008; 14(5): 923-9.

[42] Brauns H, Steinmann H. Educational Reform in France, WestGermany and the United Kingdom: updating the CASMIN educational classification. Mannheim: Mannheimer Zentrum für Europäische Sozialforschung 1997.

[43] Bundesgesundheitssurvey 1998. Public Use File [Federal Health Survey 1998. Public Use File]. Berlin: Robert Koch Institute 2000.

[44] Federal Statistical Office. Statistical Yearbook for the Federal Republic of Germany. Stuttgart: Metzler-Poeschel Verlag 2001.

[45] Hoffmeister H, Schelp FP, Mensink GB, Dietz E, Bohning D. The relationship between alcohol consumption, health indicators and mortality in the German population. Int J Epidemiol 1999; 28(6): 1066-72.

[46] Junge B, Nagel M. Das Rauchverhalten in Deutschland. [Smoking behavior in Germany]. Gesundheitswesen 1999; 61(Sonderheft 2): S121-S5.

[47] Breckenkamp J, Laaser U, Danell T. Freizeitinteressen und subjektive Gesundheit. [Hobbies and Subjective Health]. Wiesbaden: Federal Institute for Population research at the Federal Statistical Office 2001

[48] VDR Statistik Rentenbestand am 31. Dezember 2000. [VDRStatistics of Pensioners on December 31, 2000]. Berlin: Association of German Pension Insurance Companies 2005.

[49] Bergmann E, Ellert U. Sehhilfen, Hörhilfen und Schwerbehinderung. [Seeing aids, hearing aids, and disabilities]. Bundesgesundheitsblatt 2000; 43(6): 432 .

[50] Ministry of Health and Social Welfare. Arbeitsunfähigkeits-, Krankengeld- und Krankenhausfälle und -tage nach der GKV-Statistik KG2 1996 bis 2002. [Number of cases and days with sick leave and with inpatient hospitalisation, according to the statistics of the Statutory Health Insurance KG2, 1996 to 2002]. Bonn: 2003.
[51] Hautzinger M, Bailer M. ADS, Allgemeine Depressions Skala. Manual. [Center for Epidemiological Studies Depression Scale, German Version. Manual]. Weinheim: Beltz Test 1993.

[52] Hamre HJ, Witt CM, Kienle GS, Glockmann A, Willich SN, Kiene H. Predictors of outcome after 6 and 12 months following anthroposophic therapy for adult outpatients with chronic disease: a secondary analysis from a prospective observational study. BMC Research Notes 2010; 3(218): [Epub ahead of print].

[53] Hamre HJ, Witt CM, Glockmann A, Ziegler R, Willich SN, Kiene H. Anthroposophic therapy for chronic depression: a four-year prospective cohort study. BMC Psychiatry 2006; 6(57): doi:10.1186/1471-244X-6-57.

[54] Hamre HJ, Witt CM, Kienle GS, et al. Long-term outcomes of anthroposophic therapy for chronic low back pain: A two-year follow-up analysis. J Pain Res 2009; 2: 75-85.

[55] Endres HG, Diener HC, Molsberger A. Role of acupuncture in the treatment of migraine. Expert Rev Neurother 2007; 7(9): 1121-34.

[56] Nestoriuc Y, Martin A, Rief W, Andrasik F. Biofeedback treatment for headache disorders: a comprehensive efficacy review. Appl Psychophysiol Biofeedback 2008; 33(3): 125-40.

[57] Hamre HJ, Witt CM, Glockmann A, et al. Health costs in patients treated for depression, in patients with depressive symptoms treated for another chronic disorder, and in non-depressed patients: a twoyear prospective cohort study in anthroposophic outpatient settings. Eur J Health Econ 2010; 11(1): 77-94.

[58] Studer HP, Busato A. Ist ärztliche Komplementärmedizin wirtschaftlich? Eine Gesamtbeurteilung von Ergebnissen des Programms Evaluation Komplementärmedizin PEK. [Is physicianprovided complementary medicine cost-effective? An overall assessment of results of the Swiss programme for the evaluation of complementary medicine PEK]. Schweizerische Ärztezeitung 2010; 91(18): 707-711.

[59] Lipton RB, Bigal ME. The epidemiology of migraine. Am J Med 2005; 118(Suppl 1): 3S-10S.

[60] Kienle GS, Kiene H, Albonico HU. Halblützel 1980 [Experiences with "Biodoron" in an open study]. Anthroposophic medicine: effectiveness, utility, costs, safety. Stuttgart, New York, Schattauer Verlag 2006; pp. 137.

[61] Kienle GS, Kiene H, Albonico HU. Brachmann 1983 [Further experiences with "Biodoron" in clinical practice]. Anthroposophic medicine: effectiveness, utility, costs, safety. Stuttgart, New York, Schattauer Verlag 2006; pp. 127-8.

[62] Haag G. Migräne und Lebensqualität - Ergebnisse der MELTStudie [Migraine and quality of life - results of the MELT survey]. Nervenheilkunde 2004; 23(5): 297-9.

[63] Radtke A, Neuhauser H. Prevalence and burden of headache and migraine in Germany. Headache 2009; 49(1): 79-89.

[64] Lucas C, Chaffaut C, Artaz MA, Lanteri-Minet M. FRAMIG 2000: medical and therapeutic management of migraine in France. Cephalalgia 2005; 25(4): 267-79.

[65] Göbel H, Petersen-Braun M, Soyka D. The epidemiology of headache in Germany: a nationwide survey of a representative sample on the basis of the headache classification of the International Headache Society. Cephalalgia 1994; 14(2): 97-106.

[66] Hamre HJ, Glockmann A, Tröger W, Kienle GS, Kiene H. Assessing the order of magnitude of outcomes in single-arm cohorts through systematic comparison with corresponding cohorts: an example from the AMOS study. BMC Med Res Methodol 2008; 8(11): doi:10.1186/1471-2288-8-11.

(C) Hamre et al.; Licensee Bentham Open.

This is an open access article licensed under the terms of the Creative Commons Attribution Non-Commercial License (http://creativecommons.org/licenses/by-nc/3.0/) which permits unrestricted, non-commercial use, distribution and reproduction in any medium, provided the work is properly cited. 